\title{
Titanium Dioxide Nanoparticles Enhance Leakiness and Drug Permeability in Primary Human Hepatic Sinusoidal Endothelial Cells
}

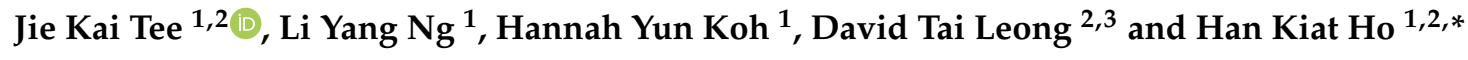 \\ 1 Department of Pharmacy, Faculty of Science, National University of Singapore, 18 Science Drive 4, \\ Singapore 117543, Singapore; jiekai.tee@u.nus.edu (J.K.T.); ngliyang.95@gmail.com (L.Y.N.); \\ hannahkyy@gmail.com (H.Y.K.) \\ 2 NUS Graduate School for Integrative Sciences \& Engineering, Centre for Life Sciences, 28 Medical Drive, \\ Singapore 117456, Singapore; cheltwd@nus.edu.sg \\ 3 Department of Chemical and Biomolecular Engineering, National University of Singapore, \\ 4 Engineering Drive 4, Singapore 117585, Singapore \\ * Correspondence: phahohk@nus.edu.sg; Tel.: +65-6516-7963
}

Received: 29 October 2018; Accepted: 26 November 2018; Published: 21 December 2018

\begin{abstract}
Liver sinusoidal endothelial cells (LSECs) represent the permeable interface that segregates the blood compartment from the hepatic cells, regulating hepatic vascular tone and portal pressure amidst changes in the blood flow. In the presence of pathological conditions, phenotypic changes in LSECs contribute to the progression of chronic liver diseases, including the loss of endothelial permeability. Therefore, modulating LSECs offers a possible way to restore sinusoidal permeability and thereby improve hepatic recovery. Herein, we showed that titanium dioxide nanoparticles $\left(\mathrm{TiO}_{2} \mathrm{NPs}\right)$ could induce transient leakiness in primary human hepatic sinusoidal endothelial cells (HHSECs). Interestingly, HHSECs exposed to these NPs exhibited reduced protein kinase B (Akt) phosphorylation, an important protein kinase which regulates cell attachment. Using a 3D co-culture system, we demonstrated that $\mathrm{TiO}_{2} \mathrm{NPs}$ diminished the attachment of HHSECs onto normal human hepatic cell LO2. To further illustrate the significance of leakiness in liver sinusoids, we showed that NP-induced leakiness promoted Sunitinib transport across the HHSEC layer, resulting in increased drug uptake and efficacy. Hence, $\mathrm{TiO}_{2} \mathrm{NPs}$ have the potential to modulate endothelial permeability within the specialized sinusoidal endothelium, especially during events of fibrosis and occlusion. This study highlighted the possible use of inorganic NPs as a novel strategy to promote drug delivery targeting the diseased liver.
\end{abstract}

Keywords: cell-material interaction; titanium dioxide nanoparticles; liver sinusoidal endothelial cells; endothelial permeability; oxidative stress; Akt pathway; cell attachment; liver fibrosis

\section{Introduction}

The liver is a vital organ involved in homeostasis through the metabolism of biomolecules and xenobiotics, regulation of blood glucose, bile production and excretion of bilirubin. With high exposure to circulating endotoxins and antigens from the gut, the liver also plays a central role in the immunological response to remove toxic agents from the bloodstream [1]. These functions are supported by the presence of discontinuous sinusoids formed by fenestrated endothelium with intercellular gaps and fragmented basement membrane to facilitate the bidirectional transport of cells and molecules across the sinusoidal barrier [2]. Lining the endothelium, liver sinusoidal endothelial cells (LSECs) are highly specialised cells that constitute the permeable barrier between the blood and liver parenchyma [3]. Under physiological conditions, they help to maintain portal pressure 
by regulating hepatic vascular tone and contribute to hepatic stellate cell (HSC) quiescence, thereby inhibiting fibrogenesis and intrahepatic vasoconstriction. However, pathological factors such as viral infections, alcoholism and schistosomiasis initiate a highly conserved wound healing response known as liver fibrosis, resulting in the activation of HSCs and excessive secretion of extracellular matrix (ECM) in the liver [4,5]. As the LSECs undergo capillarisation during liver fibrosis, profound morphological and functional changes such as the loss of fenestrae and the development of a basement membrane occur $[6,7]$. Coupled with the accumulation of ECM in the perisinusoidal space and loss of endothelial leakiness, intrahepatic resistance increases and ultimately leads to the collapse of the sinusoids. As a result, portal hypertension and hepatic dysfunction ensue as the major consequences of liver cirrhosis [8].

Early intervention of liver fibrosis is the key to preventing the onset of chronic liver disease and to promoting liver regeneration. The underlying mechanisms include the reversion of fibrogenic cells, degradation of ECM and a switch in the inflammatory environment $[9,10]$. These processes promote the restoration of liver sinusoids, thereby alleviating the fibrotic condition and contributing to hepatic recovery. Henceforth, studies have developed novel therapeutic strategies to ameliorate blood circulation in the liver and reduce complications associated with liver fibrosis [11]. Growth factors such as vascular endothelial growth factor (VEGF) and hepatocyte growth factor (HGF) have been demonstrated to alleviate inflammatory conditions and improve blood vessel formation while promoting hepatic tissue repair $[12,13]$. Drugs such as statins and obeticholic acid have been shown to modulate liver microvascular dysfunction by increasing nitric oxide $(\mathrm{NO})$ bioavailability to promote vasodilation and reduce hepatic vascular tone [14]. However, many of these strategies failed to retain an effective local concentration due to their rapid diffusion to extracellular fluids and short half-lives.

The use of inorganic nanoparticles (NPs) offers an alternative strategy to overcome the limitations of biological factors and drug molecules [15] while modulating the diseased endothelium during fibrotic progression. Previous studies have shown that titanium dioxide $\mathrm{NPs}\left(\mathrm{TiO}_{2} \mathrm{NPs}\right)$ could induce endothelial leakiness through the disruption of vascular endothelial-cadherin (VE-cadherin) and the remodelling of actin cytoskeleton [16,17]. Nanodiamonds (NDs) [18] and iron oxide NPs [19] could increase endothelial permeability through the production of reactive oxygen species (ROS) and the remodelling of microtubules. High-density silica $\mathrm{NPs}\left(\mathrm{SiO}_{2} \mathrm{NPs}\right)$ were shown to perturb endothelial cell-cell contacts by exerting a mechanic force onto the pre-tensed VE-cadherin that holds the endothelial cells together. Gold NPs (Au NPs) were shown to induce variable endothelial leakiness depending on the particle size [20]. Aside from the ability to induce endothelial leakiness, inorganic NPs have also been regarded as effective inhibitors for cellular hepatic fibrosis [21]. This further exemplified the therapeutic potential of inorganic NPs to treat liver fibrosis. While these studies highlighted the possibility of using inorganic NPs to remodel the endothelium and promote vessel leakiness, there are currently no reports suggesting the use of inorganic NPs to restore the endothelial leakiness in the fibrotic liver.

Herein, we showed that $\mathrm{TiO}_{2} \mathrm{NPs}$ induced endothelial leakiness in primary human hepatic sinusoidal endothelial cells (HHSECs). $\mathrm{TiO}_{2} \mathrm{NPs}$ were rapidly internalized into HHSECs within $30 \mathrm{~min}$ exposure and did not affect cell viability up to $72 \mathrm{~h}$. Interestingly, $\mathrm{HHSEC}$ s exposed to $\mathrm{TiO}_{2}$ NPs exhibited a reduction in phosphorylated Akt, a molecular process involved in cellular detachment. Using a 3D co-culture model of normal human hepatic cells (LO2) and HHSECs, we showed that $\mathrm{TiO}_{2}$ NPs promoted the breakaway of cells from the core culture. This phenomenon supported the increased transport of Sunitinib across a fibrotic HHSEC layer, thereby enhancing drug permeability and drug response. Therefore, this research highlights a potential use of $\mathrm{TiO}_{2} \mathrm{NPs}$ to manipulate sinusoidal leakiness for therapeutic applications during fibrotic progression. 


\section{Results}

\section{1. $\mathrm{TiO}_{2} \mathrm{NPs}$ Induced Endothelial Leakiness in the Sinusoidal Barrier}

We have observed that inorganic NPs are capable of inducing leakiness in various endothelial cell models [20], but this effect may not be generalizable across all endothelial linings. Given that vascular barriers formed by sinusoidal endothelial cells are known to be permeable and discontinuous, we asked whether $\mathrm{TiO}_{2}$ NPs could further enhance the leakiness in the HHSEC-formed endothelial layer. We first measured the hydrodynamic size and zeta potential of spherical $\mathrm{TiO}_{2} \mathrm{NPs}$ in media, and they were shown to be relatively stable up to 90 min (Figure 1A,B). This is important in order to ascertain that effects on endothelial leakiness were not attributed to progressive changes in the NP size and surface zeta potential over time. Compared to the endothelial layer established by human microvascular endothelial cells (HMVECs), we found that HHSECs exhibited a 1.5-fold increase in endothelial leakiness (Figure 2A). The enhanced leakiness was not significantly reduced with the additional coating of fibronectin, which was used for all subsequent experiments to enhance the attachment of endothelial cells. HHSECs treated with $\mathrm{TiO}_{2}$ NPs for 30 min at concentrations of $100 \mu \mathrm{M}$ and $500 \mu \mathrm{M}$ were shown to exhibit a significantly higher leakiness compared to the non-treated control (Figure 2B). We first considered how $\mathrm{TiO}_{2} \mathrm{NPs}$ could perturb the characteristic biomarkers of HHSECs (Figure S1), thereby resulting in a change in phenotype that led to endothelial leakiness. Hence, HHSECs were treated with $\mathrm{TiO}_{2}$ NPs up to $72 \mathrm{~h}$, and a combination of biomarkers previously used to identify HHSECs [22,23] from other endothelial cells, namely vascular endothelial growth factor receptors (VEGFR-1, VEGFR-2, VEGFR-3), VE-cadherin, endothelial tyrosine kinase (Tie-2), platelet endothelial cell adhesion molecule (CD31) and Stabilin-1 (Stab-1), were assessed (Figure 2C). The protein levels of these tested biomarkers did not vary significantly at earlier time points of 24 and $48 \mathrm{~h}$. However, there were observable changes to the expression of VEGFR-1, VEGFR-2 and VE-cadherin only at $72 \mathrm{~h}$. This prompted us to further investigate the biological effects of $\mathrm{TiO}_{2} \mathrm{NPs}$ on HHSECs.
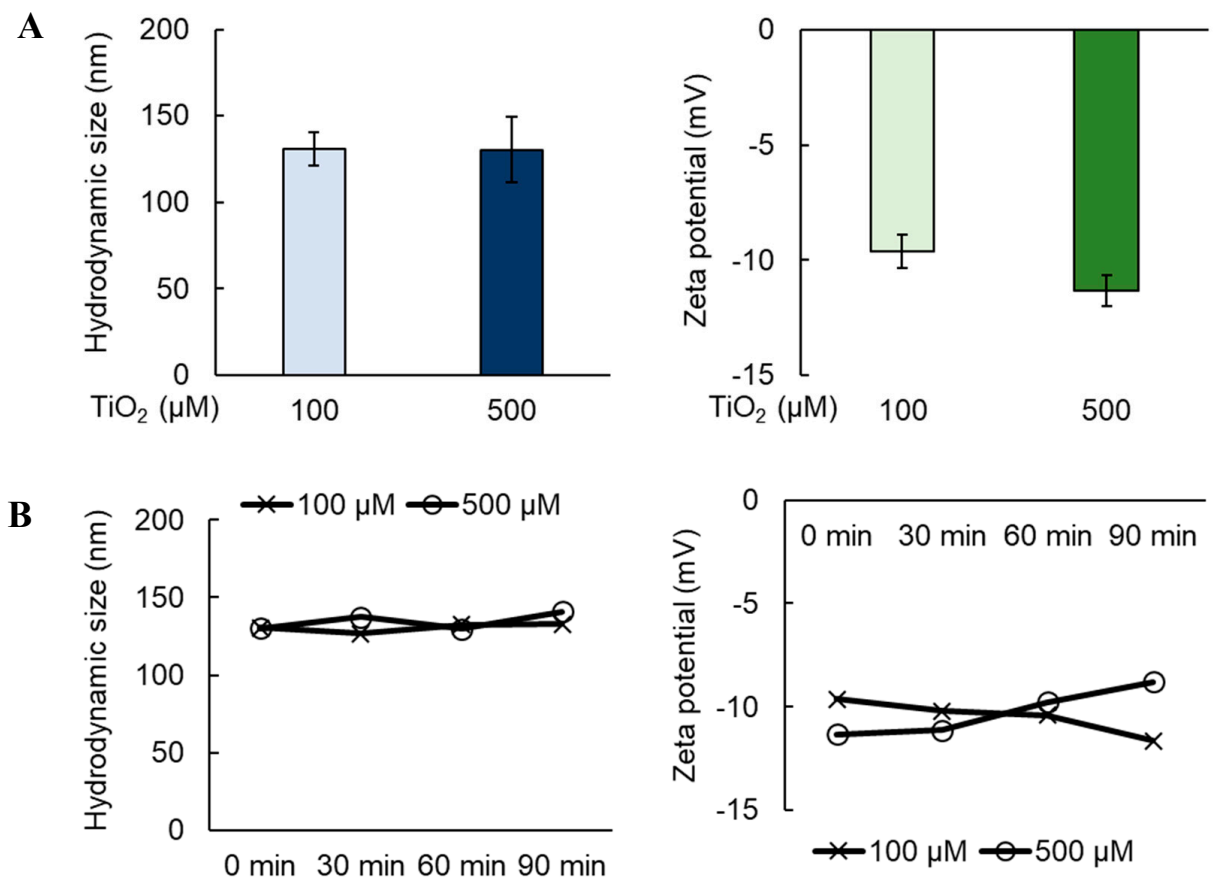

Figure 1. Characterization of titanium dioxide $\left.\mathrm{NPs}_{(\mathrm{TiO}} \mathrm{NPs}\right)$ in media. (A) Hydrodynamic size (left panel) and surface zeta potential (right panel) of $\mathrm{TiO}_{2} \mathrm{NPs}$ in media at $0 \mathrm{~min}$. Data represents mean $\pm \mathrm{SD}, n=3$. (B) The stability of $\mathrm{TiO}_{2} \mathrm{NPs}$ was measured based on hydrodynamic size (left panel) and surface zeta potential (right panel) up to 90 min post-sonication. Data represents mean $\pm \mathrm{SD}, n=3$. 
A

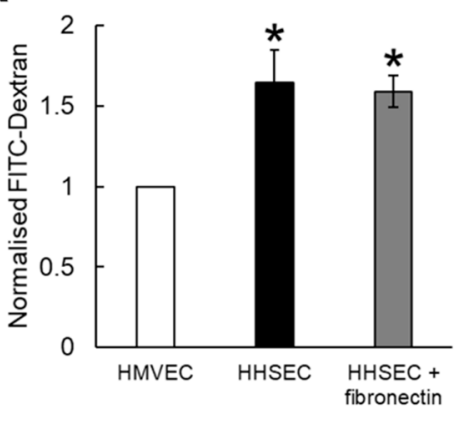

C

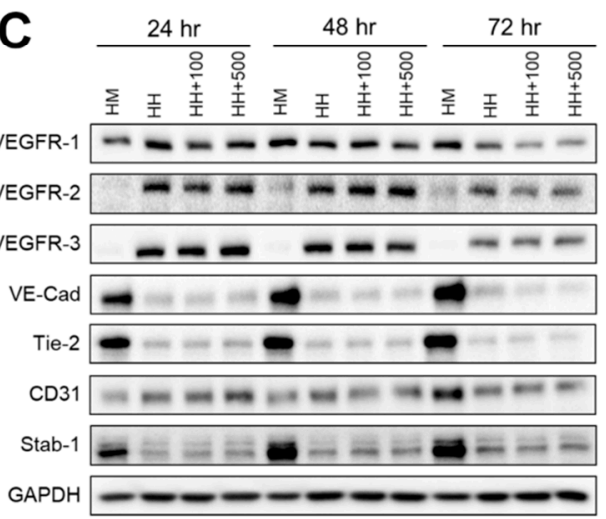

B

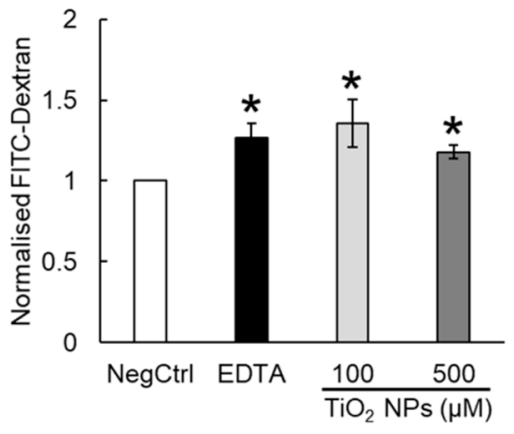

D

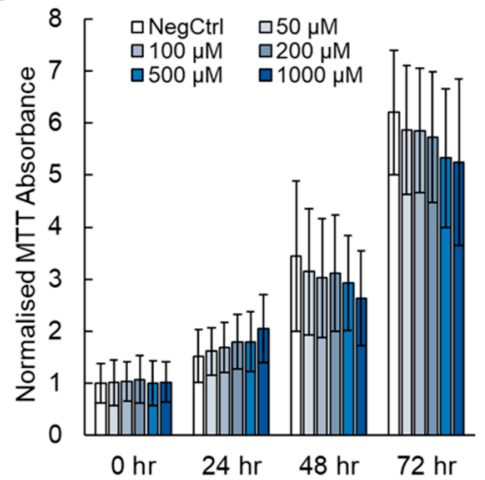

$\mathbf{E}$

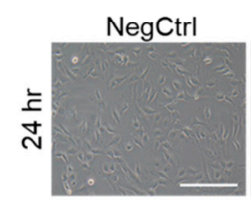

$100 \mu \mathrm{M}$

$500 \mu \mathrm{M}$
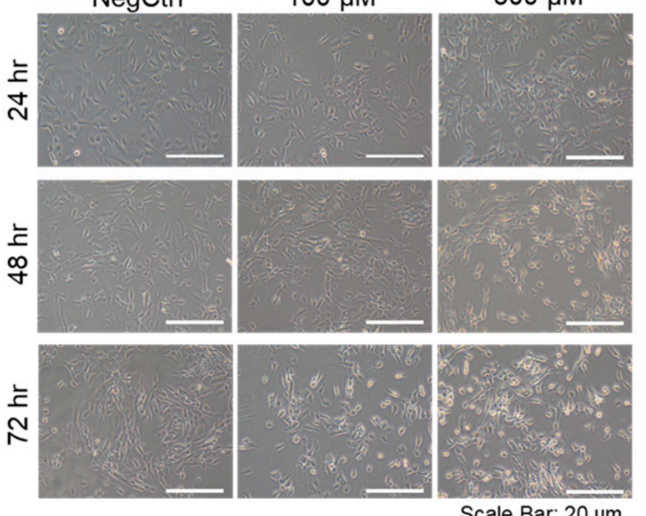

Figure 2. $\mathrm{TiO}_{2} \mathrm{NPs}$ induced endothelial leakiness in human hepatic sinusoidal endothelial cells (HHSECs) without compromising endothelial biomarkers. (A) Transwell permeability assay revealed higher fluorescein isothiocyanate (FITC)-dextran leakiness exhibited by HHSECs compared to human microvascular endothelial cells (HMVECs). Fibronectin coating did not significantly reduce the leakiness of HHSECs. (B) $\mathrm{TiO}_{2}$ NPs significantly increased the leakiness in HHSECs at two different concentrations of $100 \mu \mathrm{M}$ and $500 \mu \mathrm{M}$, compared to the untreated control (NegCtrl). EDTA was used as a positive control. (C) Western blot analyses showed that the exposure of HHSECs to $\mathrm{TiO}_{2}$ NPs did not result in observable changes to endothelial biomarkers up to $72 \mathrm{~h}$. Glyceraldehyde 3-phosphate dehydrogenase (GAPDH) was used as a loading control. (D) HHSECs treated with various concentrations of $\mathrm{TiO}_{2} \mathrm{NPs}$ up to $72 \mathrm{~h}$ did not exhibit significant difference in cell viability compared to the non-treated control (NegCtrl) at the same time point. (E) Treatment of $\mathrm{TiO}_{2} \mathrm{NPs}$ resulted in observable morphological changes to the cells leading to cellular detachment, particularly after exposure to a higher concentration $(500 \mu \mathrm{M})$ at the $72-\mathrm{h}$ timepoint. Scale bar $=20 \mu \mathrm{m}$. Data represent mean \pm SE $(n=3)$, Student's $t$-test, ${ }^{*} p<0.05$. 


\subsection{Endothelial Leakiness Was Not Due to a Decrease in Cell Viability}

Endothelial leakiness could possibly be attributed to the toxic effects of inorganic NPs in biological systems. To rule out this possibility, we treated HHSECs with various concentrations (50-1000 $\mu \mathrm{M})$ of $\mathrm{TiO}_{2}$ NPs up to $72 \mathrm{~h}$ and found no significant reduction in cell viability for all three timepoints (Figure 2D). Notably, we observed a concentration-dependent decrease in cell viability at $72 \mathrm{~h}$, suggesting that $\mathrm{TiO}_{2} \mathrm{NPs}$ may reduce the proliferation of HHSECs with prolonged exposure, albeit not statistically significantly. Cell imaging revealed that $\mathrm{TiO}_{2} \mathrm{NPs}$ caused the shrinkage and detachment of HHSECs from the surface, thereby resulting in the formation of large gaps between the cells (Figure 2E). This effect was more obvious in HHSECs treated with a higher concentration $(500 \mu \mathrm{M})$ of $\mathrm{TiO}_{2} \mathrm{NPs}_{\text {. }}$ We noticed that HHSECs were not able to form a uniform monolayer even after incubation for $72 \mathrm{~h}$. Their tendency to lose contacts with neighbouring cells over time suggested the formation of leaky endothelium when culturing for longer periods of time.

\subsection{Internalised $\mathrm{TiO}_{2} \mathrm{NPs}$ Did Not Significantly Promote Oxidative Stress}

With the high capacity of HHSECs to endocytose foreign particles [3], we investigated whether $\mathrm{TiO}_{2} \mathrm{NPs}$ could similarly be internalised into the cells. Using fluorescein isothiocyanate (FITC)-conjugated $\mathrm{TiO}_{2}$ NPs for fluorescence visualisation, we observed localisation of $\mathrm{TiO}_{2} \mathrm{NPs}$ within the cell after $30 \mathrm{~min}$ of treatment (Figure $3 \mathrm{~A}$ ). $\mathrm{TiO}_{2} \mathrm{NPs}$ were found to co-localise with lysosomes even with the co-treatment of endocytosis inhibitors monodansylcadaverine (MDC) and methyl- $\beta$-cyclodextrin $\left(\mathrm{M} \beta \mathrm{CD}\right.$ ) (Figure $\mathrm{S} 2 \mathrm{~A}, \mathrm{~B}$ ). The internalised $\mathrm{TiO}_{2} \mathrm{NPs}$ at $30 \mathrm{~min}$ did not reorganise the actin fibres; an effect that was commonly seen in other NP-induced endothelial leakiness [24,25]. However, the actin structures appeared to be more disorganised when HHSECs were treated for $3 \mathrm{~h}$, particularly at regions where $\mathrm{TiO}_{2} \mathrm{NPs}$ were localised. With the increase in endothelial permeability coupled with the remodelling of the actin fibres, we further questioned the underlying mechanisms for this effect. Intuitively, the observed morphological changes could arise as a result of physical stress or biochemical response. To determine the presence of a biochemical trigger, we explored evidence for oxidative stress as an early event. We first measured the intracellular ROS levels using $\mathrm{H}_{2}$ DCF-DA oxidative stress indicator and observed a subtle increase in ROS production with increasing concentrations of $\mathrm{TiO}_{2} \mathrm{NPs}$ (Figure 3B). However, this marginal change to the oxidative level may not account for the observed changes in the morphology of HHSECs when exposed to $\mathrm{TiO}_{2} \mathrm{NPs}_{\text {. }}$ To support this notion, we further assess the expression levels of inflammatory markers such as nuclear factor kappa-light-chain-enhancer of activated B cells (NFkB), cyclooxygenases (COX-1, COX-2) and oxidative stress markers such as nuclear factor (erythroid-derived 2)-like 2 (NRF-2) and heme oxygenase-1 (HO-1) at $3 \mathrm{~h}$ of exposure to $\mathrm{TiO}_{2} \mathrm{NPs}$. The protein levels of all markers did not change in response to $\mathrm{TiO}_{2} \mathrm{NP}$ treatment (Figure S3). Instead, we noticed an increase in expression of COX-2 and HO- 1 in the presence of endocytosis inhibitors, suggesting that oxidative balance was maintained during exposure to $\mathrm{TiO}_{2} \mathrm{NPs}$. 

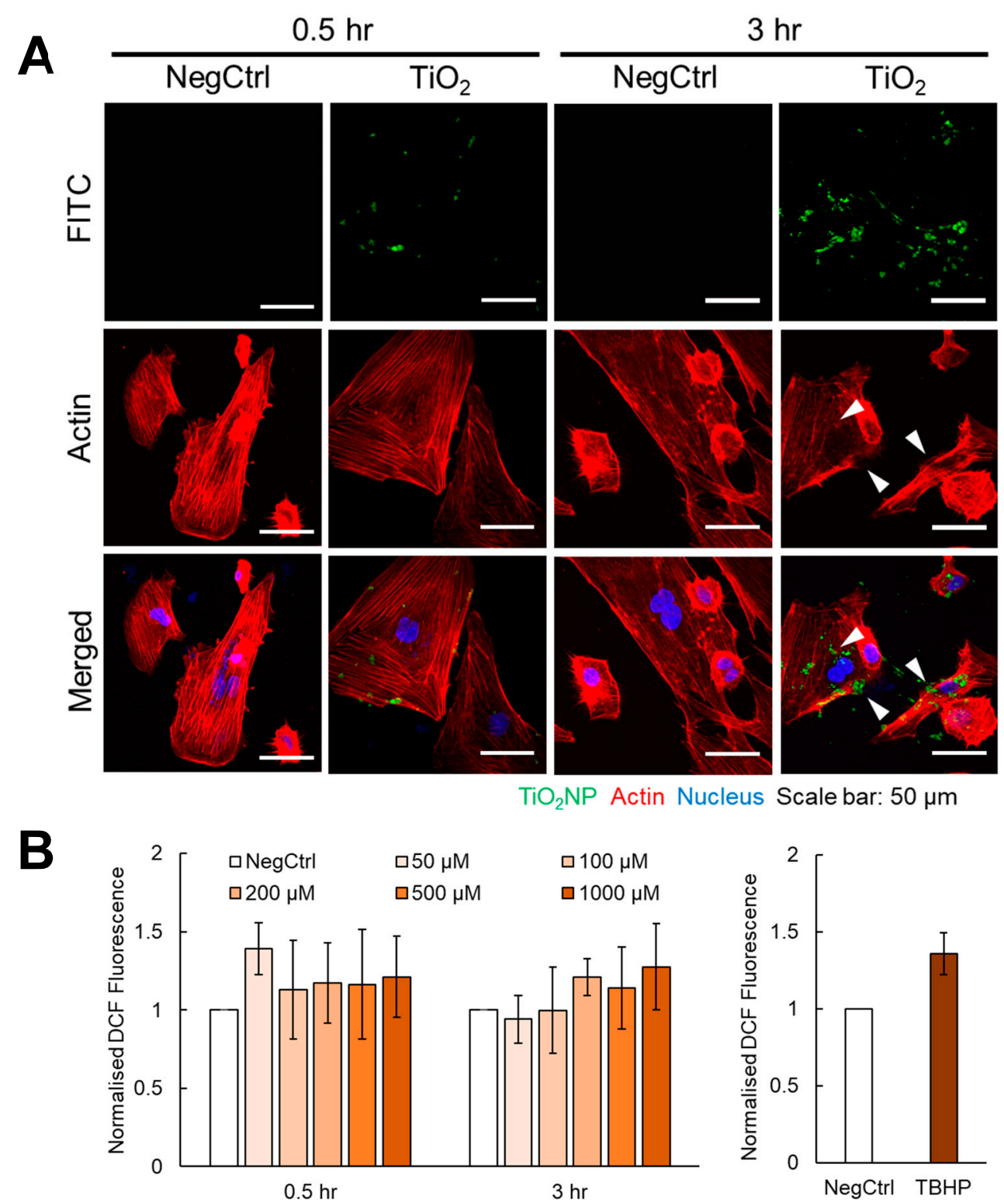

Figure 3. Internalised $\mathrm{TiO}_{2} \mathrm{NPs}$ did not significantly induce oxidative stress in HHSECs. (A) $\mathrm{TiO}_{2} \mathrm{NPs}$ conjugated with FITC (green) were internalised into HHSECs at two different timepoints of 0.5 and $3 \mathrm{~h}$. White arrows indicate possible disruption of actin fibres. Actin was stained with phalloidin dye (red) and nucleus was stained with Hoechst dye (blue). Scale bar $=50 \mu \mathrm{m}$. (B) $\mathrm{H}_{2}$ DCF-DA assay revealed no significant increase in oxidative stress exhibited by HHSECs treated with varying concentrations of $\mathrm{TiO}_{2}$ NPs at both timepoints. Tert-Butyl hydroperoxide (TBHP) was used as a positive control. Data represent mean $\pm \mathrm{SE}(n=3)$.

\section{4. $\mathrm{TiO}_{2} \mathrm{NPs}$ Weakened the Attachment of Endothelial Cells}

While we observed the cellular shrinkage of HHSECs upon exposure to $\mathrm{TiO}_{2} \mathrm{NPs}$ (Figure 2E), we postulated that there are certain cell signalling changes within the cell that could mediate this effect. Protein kinase B (Akt) signalling is one of the major pathways involved in endothelial cell attachment onto the substratum [26,27]. Therefore, a decrease in Akt phosphorylation would signal a reduction in cellular attachment. We treated HHSECs with $\mathrm{TiO}_{2}$ NPs at varying timepoints and assessed the phosphorylation of Akt. Cells treated with $\mathrm{TiO}_{2} \mathrm{NPs}$ exhibited a reduction in phosphorylated Akt, particularly at 3 and $6 \mathrm{~h}$ of NP exposure (Figure 4A). NFKB levels were also assessed to verify the absence of inflammation that could account for the induction of endothelial leakiness at short exposures. 
Since Akt phosphorylation started to reduce between $15 \mathrm{~min}$ and $3 \mathrm{~h}$ of $\mathrm{TiO}_{2} \mathrm{NP}$ exposure, we captured a more detailed time-course analysis at $15 \mathrm{~min}$ intervals up to $60 \mathrm{~min}$ (Figure 4B). The pre-treatment of cells with Akt inhibitor (LY294002) was used as a positive control to inhibit Akt phosphorylation. Indeed, we observed a time-dependent decrease in Akt phosphorylation upon $\mathrm{TiO}_{2} \mathrm{NP}$ exposure. This finding coincides with the notion that a reduction in phosphorylated Akt would signal the decrease in cellular attachment. Furthermore, intracellular calcium release downstream of Akt, coupled with the induction of oxidative stress, is often thought to mediate endothelial leakiness as this process precedes morphological changes in endothelial cell shape [18,28]. Therefore, we continued to measure intracellular calcium ions $\left(\mathrm{Ca}^{2+}\right)$ in the cell lysates. Unexpectedly, the exposure of HHSECs to two different concentrations of $\mathrm{TiO}_{2} \mathrm{NPs}$ did not promote any observable increase in intracellular $\mathrm{Ca}^{2+}$ (Figure 4C). This suggested that the endothelial leakiness observed was due to other effects mediated by a reduction in Akt phosphorylation.
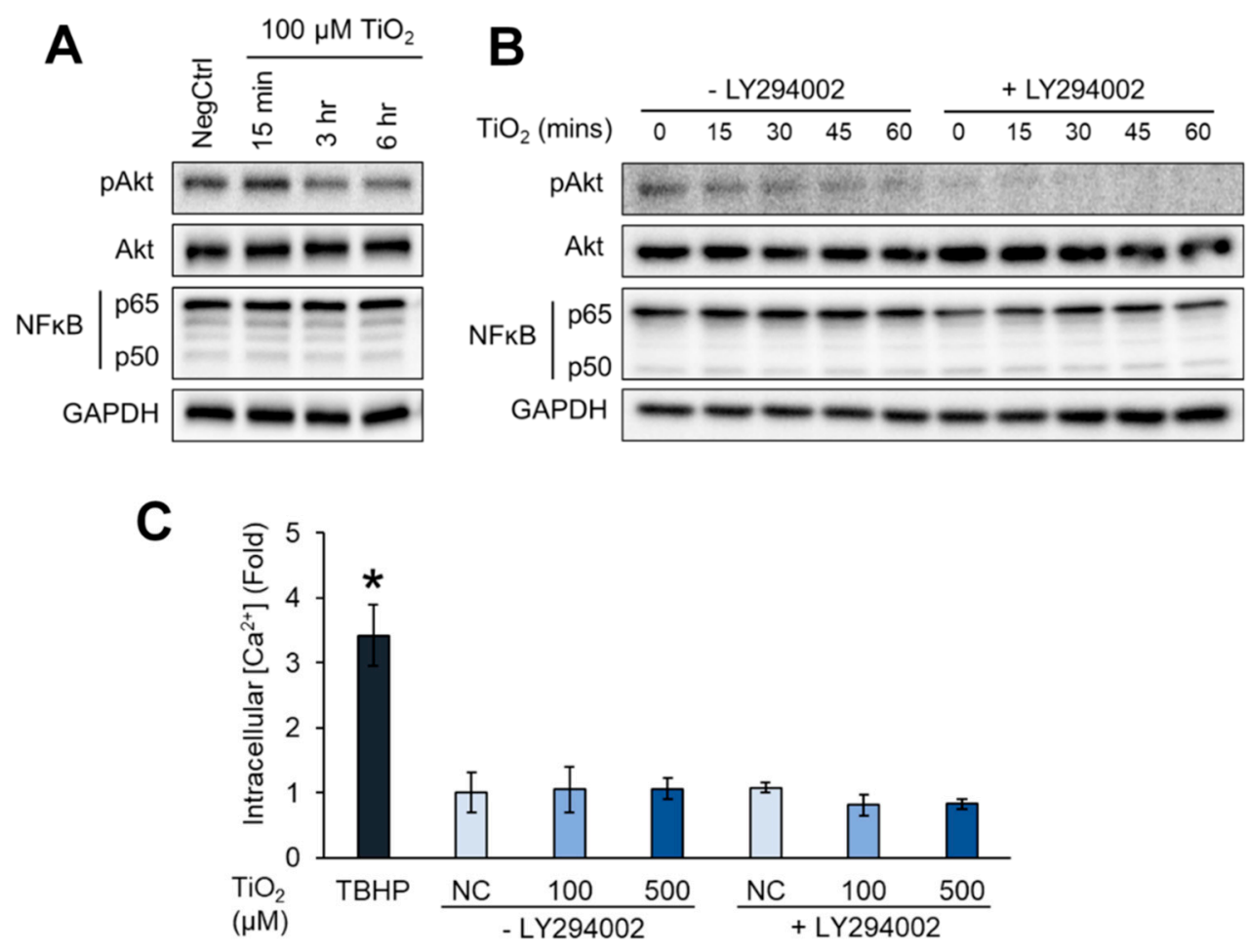

Figure 4. $\mathrm{TiO}_{2} \mathrm{NPs}$ down-regulated the protein kinase $\mathrm{B}(\mathrm{Akt})$ pathway as a late event of endothelial leakiness. (A) HHSECs exposed to $100 \mu \mathrm{M} \mathrm{TiO}_{2}$ NPs for 3 and $6 \mathrm{~h}$ showed a reduction in phosphorylated Akt. GAPDH was used as a loading control. (B) Reduction of phosphorylated Akt showed a time-dependent response upon exposure to $100 \mu \mathrm{M} \mathrm{TiO}_{2} \mathrm{NPs}$ up to $1 \mathrm{~h}$. Akt inhibitor (LY294002) was reduced as a positive control to inhibit Akt phosphorylation. (C) $\mathrm{TiO}_{2} \mathrm{NPs}$ did not induce intracellular calcium ion $\left(\mathrm{Ca}^{2+}\right)$ release after $3 \mathrm{~h}$ exposure. TBHP was used as a positive control. Data represent mean $\pm \mathrm{SE}(n=3),{ }^{*} p<0.05$.

\section{5. $\mathrm{TiO}_{2} \mathrm{NPs}$ Enhanced the Dissociation of Cell-Cell Contact in a 3D Spheroid Co-Culture Model}

Inspired by 3D spheroid co-culture systems of hepatocytes (LO2 cells) and liver endothelial cells (HHSECs) as a better representation of the in vivo liver construct [29-33], we further tested our hypothesis by establishing a co-culture model with fluorescence-labelled hepatic LO2 cells and HHSECs. After the formation of the 3D spheroid consisting of LO2 cells as the core and HHSECs as the shell, we further incubated the co-cultured model with $\mathrm{TiO}_{2} \mathrm{NPs}$ for $24 \mathrm{~h}$. Interestingly, we observed a detachment of cells, particularly the HHSECs (green cells) from the LO2 core (red cells) in both $100 \mu \mathrm{M}$ and $500 \mu \mathrm{M} \mathrm{TiO}_{2}$ NP-treated groups (Figure 5A). The disruption of the 3D-spheroid surface was more pronounced at a higher concentration $(500 \mu \mathrm{M})$ of $\mathrm{TiO}_{2} \mathrm{NPs}$. As the HHSECs appeared to 
be losing HHSEC-LO2 cell-cell contacts and migrating away from the LO2 core, the core increases its own internal cell-cell contact such that the spheroid core shrinks, resulting in a higher-intensity fluorescent red image. Using Imaris software to reconstruct a cross-sectional image of the 3D spheroid, we found that HHSECs started to break away from the surfaces of the spheroid as well as an observable tightening of the LO2 cells within the core in the $\mathrm{TiO}_{2} \mathrm{NP}$-treated groups (Figure 5B). Henceforth, these results suggested that $\mathrm{TiO}_{2} \mathrm{NPs}$ weakened the attachment of HHSECs from the endothelial layer, resulting in leakiness.

A
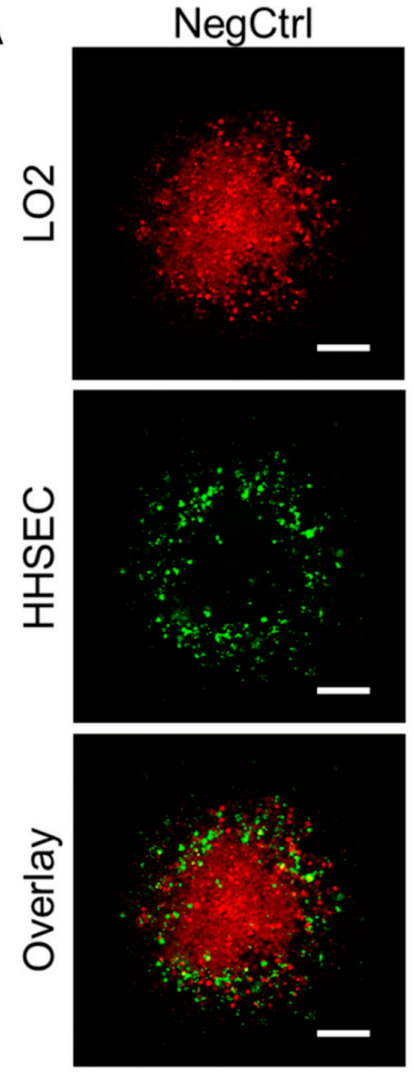

B

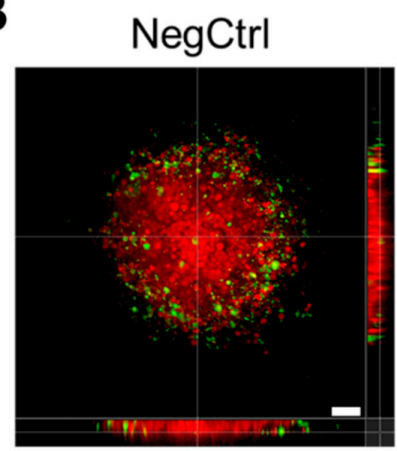

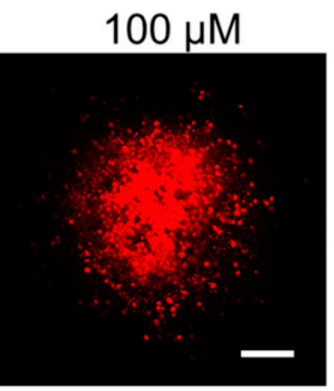
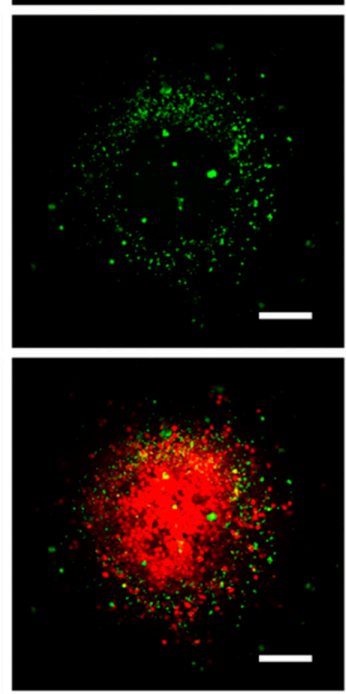

LO2 HHSEC Scale bar $=200 \mu \mathrm{m}$

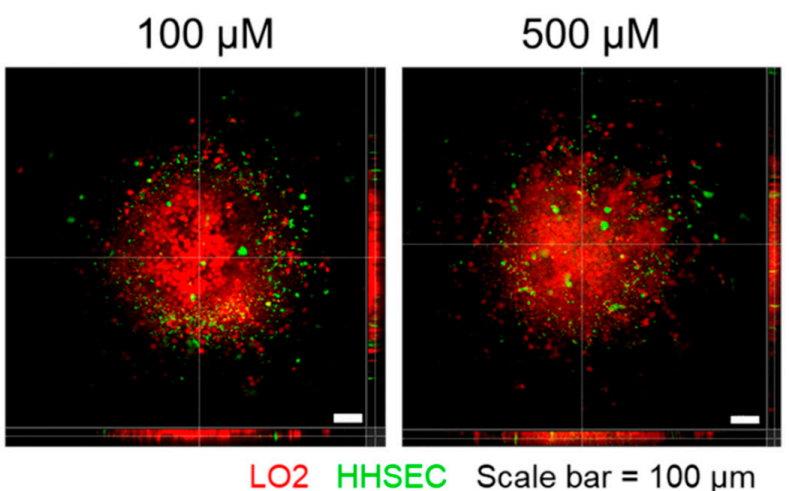

Figure 5. $\mathrm{TiO}_{2} \mathrm{NPs}$ disrupted the $3 \mathrm{D}$ co-culture model of normal human hepatic cells LO2 and HHSECs. (A) LO2 cells were stained with CellTracker orange (red) while HHSECs were stained with CellTracker green (Green). $\mathrm{TiO}_{2} \mathrm{NP}$ treatment resulted in the dispersion of both $\mathrm{LO} 2$ and HHSECs away from the core structure. Scale bar $=200 \mu \mathrm{m}$. (B) Z-stacking of multiple images to reveal a cross-section of the 3D structure showed the absence of HHSECs surrounding the $\mathrm{LO} 2$ cells upon exposure to $\mathrm{TiO}_{2} \mathrm{NPs}_{\text {. Scale }}$ bar $=100 \mu \mathrm{m}$. 


\subsection{Endothelial Leakiness Promotes Anti-Fibrotic Therapy}

Liver fibrosis is a condition worsened by the loss of endothelial leakiness and excessive deposition of ECM lining the sinusoids. Therefore, strategies to weaken the attachment of sinusoidal endothelial cells stranded in the ECM layer during liver fibrosis could provide an alternative way to favour anti-fibrotic therapy through the increase in endothelial permeability. Henceforth, the clinical benefits of such enhanced endothelial leakiness could include improving the drug delivery across the sinusoidal endothelium during treatment of liver fibrosis, especially when the ECM-rich barrier impairs drug clearance by limiting the amounts of therapeutic drugs reaching the liver parenchyma. To support this notion, we first optimised the seeding of HHSECs on transwell inserts coated with collagen and fibronectin to simulate the fibrotic condition of the endothelium (Figure S4A). The resulting endothelium exhibited a reduction in endothelial leakiness as compared to the HHSEC layer which was not pretreated with the substrate (no fibronectin). Using this fibrotic model, we showed that $100 \mu \mathrm{M} \mathrm{TiO}_{2}$ NPs could increase endothelial permeability within $30 \mathrm{~min}$ (Figure S4B). This NP-induced leakiness required the presence of HHSECs as we showed that there was no increase in leakiness in the insert with only the ECM coating, which further suggested that the ECM layer barrier was compromised by the endothelial cells. In order to demonstrate the application of NP-induced leakiness in the context of drug delivery, we first treated the HHSEC layer with $\mathrm{TiO}_{2} \mathrm{NPs}_{\text {for }} 30$ min to induce endothelial leakiness before assessing the transport of Sunitinib across the leaky endothelium. After incubation with Sunitinib for another $30 \mathrm{~min}$, we detected a significantly higher concentration of Sunitinib from a range of $1 \mu \mathrm{M}$ to $1.24 \mu \mathrm{M}$ across the $\mathrm{TiO}_{2} \mathrm{NP}$-treated endothelium, suggesting that an increased amount of Sunitinib have diffused across the endothelial barrier (Figure 6A). Given that the increase was approximately 1.24-fold, we further demonstrated the efficacy of our strategy by using the relative concentrations of Sunitinib to treat transforming growth factor-beta 1 (TGF- $\beta 1$ )-activated hepatic stellate cells LX2, the key fibrotic cell that drives liver fibrosis [4]. Interestingly, there was an observable reduction in TGF- $\beta 1$-induced $\alpha$-smooth muscle actin ( $\alpha$ SMA) upon exposure from 1 to $2 \mu \mathrm{M}$ of Sunitinib (Figure 6B), a key biomarker of stellate cell activation and subsequent fibrosis. The therapeutic effects of such increase in Sunitinib concentration was further highlighted in our 3-(4,5-dimethylthiazol-2-yl)-2,5-diphenyltetrazolium bromide (MTT) assay, in which we showed a significant reduction of LX2 viability beyond $1 \mu \mathrm{M}$ of Sunitinib (Figure 6C). Therefore, such an increase in Sunitinib concentration caused by a subtle increase in endothelial leakiness could be translated to a significant enhancement of drug efficacy. 

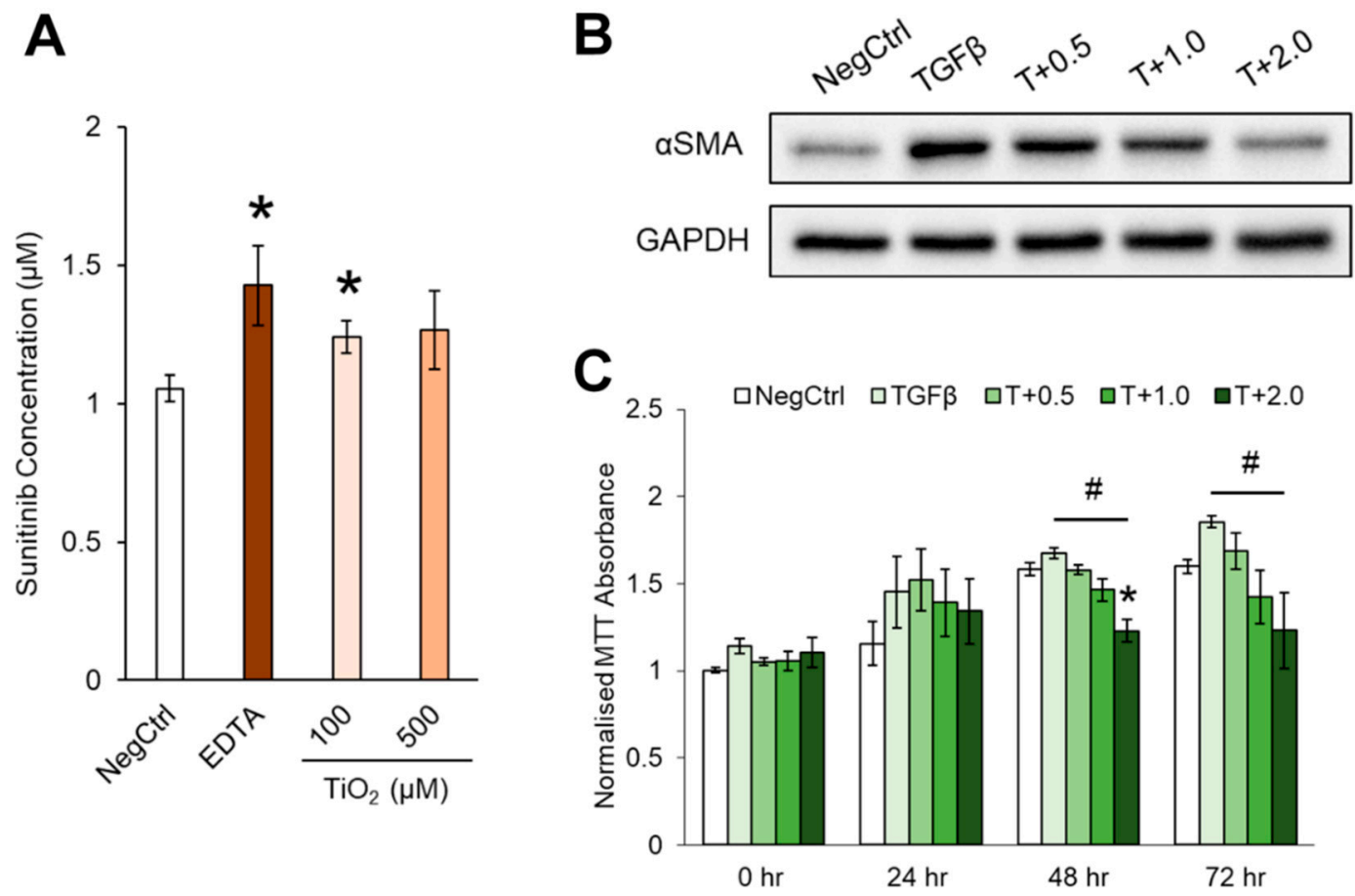

Figure 6. $\mathrm{TiO}_{2} \mathrm{NP}$-induced leakiness promoted Sunitinib transport across the HHSEC barrier. (A) Endothelial leakiness from HHSECs treated with $\mathrm{TiO}_{2} \mathrm{NPs}$ significantly increased the transport of Sunitinib across the endothelial barrier, compared to the non-treated control (NegCtrl). EDTA was used as a positive control. Data represent mean \pm SE $(n=3)$, one-tail equal variance Student's $t$-test, ${ }^{*} p<0.05$. (B) The increase in Sunitinib concentration was found to reduce pro-fibrotic marker $\alpha$-SMA in transforming growth factor-beta 1 (TGF- $\beta 1$ )-activated hepatic stellate cells LX2 after $24 \mathrm{~h}$ treatment. Untreated LX2 cells were used as the negative control (NegCtrl). (C) Increased concentrations of Sunitinib were also found to reduce the viability of TGF- $\beta 1$-activated LX2 cells up to $72 \mathrm{~h}$. Data represents mean $\pm \mathrm{SE}(n=3)$, one-way ANOVA with Tukey HSD test, ${ }^{*} p<0.05$ denotes significance against non-treated control at respective timepoint, ${ }^{\#} p<0.05$ denotes significance against TGF- $\beta 1$ treated control.

\section{Discussion}

The development of a fibrotic liver encompasses a spectrum of biological changes in the microenvironment which converge on a pivotal event of diminished blood flow through the sinusoidal vessels. This phenomenon not only compromises intrahepatic functions (e.g., xenobiotic clearance), but can also trigger extrahepatic problems (e.g., portal hypertension and edema). Strategies to modulate liver microvascular dysfunction and regulate vascular tone could thus help to alleviate the fibrotic condition. In this study, we first demonstrated that $\mathrm{TiO}_{2} \mathrm{NPs}$ could enhance endothelial leakiness in HHSEC-formed endothelium within a short time frame. Secondly, endothelial leakiness was not accompanied with the induction of oxidative stress, a phenomenon normally observed with the use of inorganic NPs in biological systems [34]. Thirdly, HHSECs treated with $\mathrm{TiO}_{2} \mathrm{NPs}$ exhibited a profound reduction in Akt phosphorylation, which potentially mediates the loss of cellular attachment from the substratum, resulting in further leakiness. With these key points in mind, we anticipate that such biochemical perturbations could be further exploited to promote the delivery of anti-fibrotic drugs such as Sunitinib across the leaky sinusoidal barrier.

Although previous studies have shown that NP-induced endothelial leakiness was attributed to the loss of VE-cadherin at the cell-cell contacts [16,35], we observed a reduction in VE-cadherin expression only at $72 \mathrm{~h}$ (Figure 2C), independent from the enhanced leakiness observed within $30 \mathrm{~min}$ (Figure 2B). VE-cadherin is an adherens junction protein that plays an important role in maintaining the integrity of endothelial cell junctions [36]. Despite being the major cadherin expressed by HHSECs, 
the relatively low expression of VE-cadherin could be due to the lack of classical adherens junctions in the sinusoidal endothelium [22]. This accounts for the leaky phenotype observed in HHSECs as well as their limited involvement during NP-induced endothelial leakiness. In order to observe an even leakier phenotype in the HHSECs layer, $\mathrm{TiO}_{2} \mathrm{NPs}$ would have significantly altered the morphology of the endothelial cells. As such, we postulated that $\mathrm{TiO}_{2} \mathrm{NPs}$ could have weakened cellular attachment from the substratum. Wang et al. showed that negatively charged Au NPs induced greater endothelial leakiness than their positive counterparts due to a series of repulsive-sedimentary interactions between the inorganic NPs and glycocalyx found on the cell surface, both of which are negatively charged [37]. Similarly, Voijt et al. demonstrated that polyanionic lipid NPs exert electrostatic repulsion to promote hydrophobic interaction with the lipid raft structure of caveolae, which are small invaginations highly expressed on the endothelial cell membrane [38]. Hence, endothelial leakiness could be induced

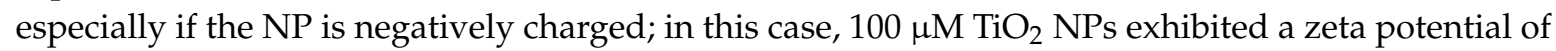
$-10 \mathrm{mV}$ in media (Figure $1 \mathrm{~A}, \mathrm{~B}$ ). Therefore, the $\mathrm{TiO}_{2} \mathrm{NP}$-induced endothelial leakiness observed in our current study could well be attributed to strong NP-cell interactions which resulted in the separation of endothelial cells away from each other.

The application of inorganic NPs on the liver sinusoids during fibrosis poses as a double-edged sword. On one hand, NPs could help to modulate endothelial permeability and restore vascular tone. On the other hand, the excessive use of NPs could lead to undesirable biological stress on the endothelial cells. Henceforth, inducing endothelial leakiness without exerting significant cellular toxicity and other adverse consequences is an important therapeutic consideration to promote the clinical use of inorganic NPs. Our Western blot analyses (Figure 2C) revealed that these NPs did not induce endothelial dysfunction as several of these endothelial biomarkers were not significantly perturbed. Furthermore, our MTT cell viability assays (Figure 2D) showed that $\mathrm{TiO}_{2} \mathrm{NPs}_{\text {up }}$ to $1000 \mu \mathrm{M}$ did not induce significant reduction in the proliferation of HHSECs. Instead, there was observable cell proliferation at all NP concentrations over the treatment time up to $72 \mathrm{~h}$, suggesting that $\mathrm{TiO}_{2} \mathrm{NPs}$ did not affect the ability of the cells to proliferate. In addition, treatment of $\mathrm{TiO}_{2} \mathrm{NPs}$ did not induce significant ROS production (Figure 3B) or exert any observable changes to the protein biomarkers of oxidative stress (Figure S3). Therefore, we rule out the possibility that $\mathrm{TiO}_{2} \mathrm{NPs}_{\mathrm{N}}$ could affect cell survival within these time points. In other words, the induced endothelial leakiness was not attributed to the reduction in cell viability or generation of oxidative stress. This is in stark contrast to other established studies linking oxidative stress and endothelial permeability, in which the degree of leakiness is attributed to the ROS production profile. Liu et al. has showed that $\mathrm{SiO}_{2} \mathrm{NPs}$ disrupted the blood-brain barrier through the loss of tight junctions and cytoskeleton arrangement, accompanied by an increase in inflammatory response and presence of oxidative stress [39]. Nevertheless, such biological stress can be regulated through the surface functionalisation of NPs to induce a tunable endothelial permeability favourable for drug delivery strategies [18]. As such, we speculated that a well calibrated use of $\mathrm{TiO}_{2} \mathrm{NPs}$ could achieve a favourable stress response which then leads to the desired endothelial permeability.

Our results demonstrated that $\mathrm{TiO}_{2} \mathrm{NPs}$ can be used at a lower concentration $(100 \mu \mathrm{M})$ to induce a similar leakiness effect compared to higher concentrations. This ensures that the targeted HHSECs could retain their physiological roles in mediating an important protective function as an endothelial barrier of the liver sinusoids while minimizing the bioaccumulation of NPs [40]. A study has demonstrated that $40 \mu \mathrm{g} / \mathrm{mL}$ of $20 \mathrm{~nm}$ Au NPs caused a 50\% increase leakiness in human umbilical vein endothelial cells (HUVECs) and a $40 \%$ decay in cell-ECM adhesive forces without affecting cell viability significantly [24]. The observed endothelial leakiness was induced through unbalanced intracellular tensions and paracellular forces, coupled with actin rearrangement mediated by the Rho-associated protein kinase (ROCK)-dependent pathway. This study coincides with our endothelial permeability (Figure 2B) and cell attachment experiments (Figure 5A,B) that NPs could weaken cell-cell and cell-ECM contacts to promote endothelial leakiness. Our immunofluorescence results (Figure 3A) also revealed the disruption of the actin cytoskeleton, especially at sites where the $\mathrm{TiO}_{2}$ 
NPs were internalised, suggesting the close interaction of actin fibres and the NPs in contributing to the phenotypic changes. Furthermore, we hypothesized that $\mathrm{TiO}_{2} \mathrm{NPs}$ could induce leakiness by reducing the activation of Akt (Figure 4A,B), a major pathway involved in cell survival and attachment. Indeed, inorganic NPs such as $\mathrm{SiO}_{2}$ NPs have been previously shown to disrupt endothelial cell function and promote vascular permeability through the inhibition of the phosphoinositide 3-kinase (PI3K)/ Akt signalling pathway [41]. Cell attachment studies on endothelial tyrosine kinase Tie2-mediated anchoring have also reported the significance of the Akt pathway to provide a stabilizing signal in the endothelial cells [26], as well as being preferentially activated by dimerized Tie2 in the presence of cell-cell contacts [27]. Furthermore, other studies have reported Akt-dependent mechanisms involving the downregulation of eNOS activity which could direct the loss of cellular attachment from the substratum [42,43]. Taken together, these studies have specifically pinpointed the involvement of Akt in cellular detachment. Therefore, our findings are consistent with these observations, where a mechano-transduction process may drive $\mathrm{TiO}_{2} \mathrm{NP}$-induced endothelial leakiness towards a structural and a functional change.

Endothelial leakiness has been phenotypically attributed to the loss of cell-cell contacts due to the disruption of adherens junction proteins [16], cytoskeleton rearrangement resulting in cell retraction [18], or the weakening of cell adhesion from the substratum [24]. Although 2D transwell assay is regarded as a gold standard technique to assess endothelial barrier function [44], this assay may not capture the key finding of cell detachment that addressed the leaky phenomenon. Henceforth, endothelial leakiness was further shown in the 3D co-culture model comprising hepatic LO2 cells and HHSECs in which the exposure to $\mathrm{TiO}_{2} \mathrm{NPs}$ caused the disruption of the core-shell model and the dispersion of HHSECs away from the structure. (Figure 5). The co-culturing of hepatocytes and endothelial cells has been previously reported to sustain the long-term viability of cells while mimicking the liver sinusoid conditions. Kang et al. demonstrated that primary rat hepatocytes and LSECs can be cultured together with cells exhibiting normal morphology up to 39 days [30]. Another study has also showed the use of tricultures comprising of hepatocytes, fibroblast and endothelial cells to elucidate reciprocal cellular interactions between the different cell types [45]. From our study, we demonstrated that $\mathrm{TiO}_{2} \mathrm{NP}$-induced endothelial leakiness is not limited to monolayer cultures as the results showed substantial detachment of cells from the LO2/HHSEC co-culture model (Figure 5). This finding confirmed the decrease in cell-cell interactions, thereby disrupting the intricate 3D conformation.

In order to widen the applicability of enhanced leakiness caused by $\mathrm{TiO}_{2} \mathrm{NPs}$, we assessed whether such leakiness could promote the transport of therapeutic agents across the HHSEC layer. This phenomenon is particularly important in diseases featuring a reduction in endothelial permeability, such as liver fibrosis. During fibrotic progression, multiple cellular changes occur in the liver microenvironment, including a self-perpetuating cycle between the capillarized LSECs and activated HSCs which stimulate each other [46]. As a result, the loss of the basement membrane and excessive secretion of ECM resulted in a drastic reduction in endothelial leakiness within the liver sinusoids. To prove that the $\mathrm{TiO}_{2}$ NP-induced endothelial leakiness provides a window of opportunity for therapeutic drugs to enter, we first constructed a monolayer of HHSECs seeded onto collagen and fibronectin-coated transwell. A significant reduction of endothelial leakiness was observed in the collagen/fibronectin-coated transwell, which mimicked the fibrotic condition of the liver sinusoid (Figure S4A). The induction of endothelial leakiness by $\mathrm{TiO}_{2} \mathrm{NPs}$ was observed to be cell-dependent (Figure S4B), thus showing that cellular movement is required to provide the necessary force to dislodge the cells from attachment to the ECM or from neighbouring cells. Using Sunitinib as the drug model, we further demonstrated that NP-induced endothelial leakiness could promote drug transport across the endothelium to enhance the efficacy of anti-fibrotic therapeutics (Figure 6A). Sunitinib is a well-known multitarget tyrosine kinase inhibitor commonly investigated for its anti-fibrotic effects [47]. Enhancing endothelial leakiness may help to overcome the therapeutic limitations imposed by liver fibrosis where the uptake and accumulation of drugs within the cells is compromised [48]. In the 
presence of $\mathrm{TiO}_{2} \mathrm{NP}$ treatment, we demonstrated a 1.24-fold increase in Sunitinib concentration at the bottom of the transwell chamber (Figure 6A). Clearly, there was an observable decrease in both the fibrotic markers (Figure 6B) and cellular viability (Figure 6C) of activated LX2 upon exposure to Sunitinib, even at low doses of 1 to $2 \mu \mathrm{M}$, suggesting that a minute increase of endothelial leakiness may still result in a significant enhancement of drug efficacy. Henceforth, these findings reveal a possible use of NP-induced endothelial leakiness as a relatively safe and exploitable strategy to improve drug delivery across an otherwise impenetrable vascular barrier in diseased conditions.

\section{Materials and Methods}

\subsection{Cell Culture and Reagents}

Human hepatic sinusoidal endothelial cells (HHSECs) (ScienCell Research Laboratories, Carlsbad, CA, USA) were cultured in endothelial cell medium (ScienCell Research Laboratories, CA, USA) supplemented with $5 \%$ fetal bovine serum (FBS) according to the manufacturer's instructions. Human hepatic cells, LO2, were received as a kind gift from A/Prof. Victor Yu (National University of Singapore, Department of Pharmacy, Singapore) and cultured in high glucose Dulbecco's modified Eagle's medium (DMEM) (Sigma-Aldrich, St. Louis, MO, USA) supplemented with $10 \%$ FBS. Human hepatic stellate cells, LX2, were received as a kind gift from Prof. Scott Friedman (Mount Sinai Hospital, New York, NY, USA) and cultured in low-serum DMEM supplemented with $1 \%$ FBS. All cells were incubated in a humidified atmosphere at $37{ }^{\circ} \mathrm{C}$ with $5 \% \mathrm{CO}_{2}$. LX2 cells were activated with $2 \mathrm{ng} / \mathrm{mL}$ transforming growth factor beta 1 (TGF- $\beta 1$ ) (Merck Millipore, Burlington, MA, USA) for $24 \mathrm{~h}$. The following inhibitors were used: monodansylcadaverine (MDC), methyl- $\beta$-cyclodextrin (M $\beta C D$ ) (Sigma-Aldrich, St. Louis, MO, USA) and LY294004 (Cell Signaling Technology, Danvers, MA, USA). The following antibodies were used: anti-Flt-1/VEGFR-1, anti-Flk-1/VEGFR-2, anti-Flt-4/VEGFR-3, anti-stabilin-1, anti-COX-1 and anti-COX-2 (Santa Cruz Biotechnology, Dallas, TX, USA); anti-VE-cadherin, anti-Tie-2 (Western blot), anti-CD31, anti-NFKB, anti-HO-1, anti-phospho-Akt, anti-Akt, anti-GAPDH, secondary anti-mouse and anti-rabbit (Cell Signaling Technology, MA, USA); anti-Tie-2 (Imaging) (Sino Biological, Beijing, China); anti-NRF-2 (MBL international, Woburn, MA, USA); anti- $\alpha$ SMA (Agilent Dako, Santa Clara, CA, USA).

\subsection{Preparation of $\mathrm{TiO}_{2} \mathrm{NPS}$}

Titanium dioxide nanoparticles $\left(\mathrm{TiO}_{2} \mathrm{NPs}\right)$ were first prepared by dispersing $5 \mathrm{mg}$ of p25 $\mathrm{TiO}_{2}$ nanopowder (MR: 79.87) with primary size of $21 \mathrm{~nm}$ (Sigma-Aldrich, St. Louis, MO, USA) in $1 \mathrm{~mL}$ of water to give $62.5 \mathrm{mM}$ concentration and sonicated using Sonic Dismembrator model 100 (Thermo Fisher Scientific, Waltham, MA, USA) for $45 \mathrm{~s}$. Subsequently, the suspension was further diluted with endothelial cell media (ScienCell Research Laboratories, CA, USA) into either $100 \mu \mathrm{M}$ or $500 \mu \mathrm{M}$ and sonicated for another $45 \mathrm{~s}$. Hydrodynamic size and surface zeta potential of the NPs were then measured using Zetasizer Nano ZS90 size analyzer (Malvern Panalytical, Malvern, England). FITC was covalently tagged onto $\mathrm{TiO}_{2}$ NPs according to the previous study [16].

\subsection{Transwell Permeability Assay}

Endothelial cells were seeded at a density of thirty thousand cells $/ \mathrm{cm}^{2}$ onto 24 -well $6.5 \mathrm{~mm}$ transwell insert, polyester filter with $0.4 \mu \mathrm{m}$ pores (Corning, Corning, NY, USA) for 3 days to form a confluent layer. Thereafter, $\mathrm{TiO}_{2} \mathrm{NPs}$ were mixed together with $1 \mathrm{mg} / \mathrm{mL}$ fluorescein isothiocyanate (FITC)-dextran (MW: 40,000; Sigma-Aldrich, St. Louis, MO, USA) in media and added to the cells for $30 \mathrm{~min}$. Subsequently, $100 \mu \mathrm{L}$ of media was collected from the lower compartment of the transwell and placed into a 96-well black plate. Fluorescence signal was then quantified using Hidex Sense microplate reader (Hidex, Turku, Finland) at Ex490/Em520 nm and data was normalised with the untreated control. 


\subsection{Western Blot}

Cells were harvested and lysed with radioimmunoprecipitation assay (RIPA) buffer containing $0.1 \%$ sodium dodecyl sulfate (SDS) $\mathrm{w} / \mathrm{v}, 0.5 \%$ Sodium deoxycholate $\mathrm{w} / \mathrm{v}$ and $1 \% \mathrm{NP}-40 \mathrm{v} / \mathrm{v}$. Thereafter, protein lysates were loaded into 10\% SDS-PAGE polyacrylamide gel (Bio-Rad Laboratories, Hercules, CA, USA) and run at $130 \mathrm{~V}$ for $2 \mathrm{~h}$. Subsequently, a "sandwich" method was used to transfer the proteins onto polyvinylidene difluoride (PVDF) membrane (Thermo Fisher Scientific, Waltham, MA, USA) at $100 \mathrm{~V}$ for $2 \mathrm{~h}$ at $4{ }^{\circ} \mathrm{C}$. The membrane was then block with $5 \%$ bovine serum albumin $\mathrm{w} / \mathrm{v}$ in Tris-buffered saline (1st Base, Singapore) containing $0.1 \%$ tween v/v (TBST) for $1 \mathrm{~h}$. After blocking, the membrane was incubated with the respective primary antibody $(1: 1000)$ diluted with $2 \% \mathrm{BSA} w / \mathrm{v}$ in TBST overnight. The membrane was washed thrice with TBST and incubated with secondary antibody $(1: 10,000)$ for $1 \mathrm{~h}$. After washing the membrane again thrice with TBST, Western Lightning Plus-ECL reagent (Perkin Elmer, Waltham, MA, USA) was added and the membrane was exposed with G:Box Gel imaging system (Syngene, Bangalore, India).

\subsection{Cell Viability Assay}

The 3-(4,5-dimethylthiazol-2-yl)-2,5-diphenyltetrazolium bromide (MTT) assay (Duchefa Biochemie, Haarlem, Netherlands) was performed to measure cell viability. Five thousand cells/well were first seeded in a 96-well plate overnight before treatment with the respective compounds at different concentrations for 24, 48 and $72 \mathrm{~h}$. After treatment, the media was removed and replaced with fresh media containing $0.5 \mathrm{mg} \mathrm{mL}^{-1}$ of MTT dye for another $3 \mathrm{~h}$ at $37^{\circ} \mathrm{C}$. The dye was then removed and $200 \mu \mathrm{L}$ of dimethyl sulfoxide (DMSO) (Fisher Scientific, Hampton, NH, USA) was added to dissolve the formazan salt. Absorbance was measured using Hidex sense microplate reader (Hidex, Turku, Finland) and data was normalised with the untreated control.

\subsection{Immunofluorescence Imaging}

Five thousand cells/well of HHSECs seeded onto 8-well chamber slides (Thermo Fisher Scientific, Waltham, MA, USA) were fixed with $4 \%$ paraformaldehyde w/v (Sigma-Aldrich, St. Louis, MO, USA) and permeabilized with $0.2 \%$ Triton X-100 v/v in PBS (Sigma-Aldrich, St. Louis, MO, USA) for $15 \mathrm{~min}$ each. Subsequently, the cells were blocked with $2 \%$ BSA w/v in PBS on ice for $1 \mathrm{~h}$. After blocking, respective primary antibody (1:200) diluted in $0.2 \% \mathrm{w} / \mathrm{v}$ BSA and $0.1 \% \mathrm{v} / \mathrm{v}$ Triton X-100 in PBS was added and incubated overnight at $4{ }^{\circ} \mathrm{C}$. Cells were washed twice with PBS and incubated with CF568 phalloidin (Biotium, Fremont, CA, USA), Hoechst 33342 dye (Sigma-Aldrich, St. Louis, MO, USA) and/or Alexa 488 chicken anti-rabbit/mouse (1:400) for $1 \mathrm{~h}$ at room temperature. After washing twice with PBS, $10 \mu \mathrm{L}$ of Fluoromount ${ }^{\mathrm{TM}}$ aqueous mounting medium (Sigma-Aldrich, St. Louis, MO, USA) was added onto each sample and fluorescence images were captured with Olympus Fluoview FV1000 confocal microscope (Olympus, Tokyo, Japan).

\subsection{Oxidative Stress Assay}

General oxidative stress indicator $\left(\mathrm{CM}-\mathrm{H}_{2} \mathrm{DCFDA}\right)$ assay (Thermo Fisher Scientific, Waltham, MA, USA) was performed to assess the production of ROS in HHSECs upon exposure to $\mathrm{TiO}_{2} \mathrm{NPs}_{\text {. }}$ ten thousand cells/well were seeded onto 96-well black, clear bottom plate for 2 days. After treatment with $\mathrm{TiO}_{2}$ NPs, the cells were washed with PBS and incubated with $10 \mu \mathrm{M} \mathrm{CM}-\mathrm{H}_{2}$ DCFDA reagent and Hoechst 33342 dye (Sigma-Aldrich, St. Louis, MO, USA) for $30 \mathrm{~min}$. The reagents were removed and cells were wash twice with PBS. Lastly, fluorescence signal was quantified at Ex485/Em535 nm using a Hidex sense microplate reader (Hidex, Turku, Finland) to detect DCF and normalised against cell number detected from Hoechst dye at Ex355/Em460 nm. Data were normalised against the untreated control. 


\subsection{Calcium Ion Measurement}

Intracellular calcium release was measured using a calcium quantification assay kit (Abcam, Cambridge, MA, USA) according to the manufacturer's instructions. Briefly, HHSECs were first harvested with RIPA buffer to obtain the cell lysates. $50 \mu \mathrm{L}$ of lysate was mixed with $50 \mu \mathrm{L}$ of assay reaction buffer containing rhodamine red indicator inside a 96-well black plate and incubated for $15 \mathrm{~min}$ in the dark at room temperature. Fluorescence signal was then quantified at Ex535 nm/Em590 nm using Hidex sense microplate reader (Hidex, Turku, Finland) and data was normalised against untreated control.

\subsection{D Co-Culture Model}

The 3D co-culture model was constructed using a two-step forced aggregation of LO2 cells and HHSECs seeded separately at 24-h intervals in media. Firstly, LO2 cells were pre-labelled with $5 \mu \mathrm{M}$ of CellTracker Orange (Life Technologies, Carlsbad, CA, USA) before adding to the non-adherent 96-well plate at a seeding density of twenty thousand cells/well. After $24 \mathrm{~h}$, a spheroid containing LO2 cells was formed. Secondly, the media was carefully removed and replaced with fresh media containing HHSECs pre-labelled with $5 \mu \mathrm{M}$ of CellTracker Green (Life Technologies, CA, USA) at a seeding density of twenty thousand cells/well for another $24 \mathrm{~h}$. Multiple fluorescence images were taken using Olympus Fluoview FV1000 confocal microscope (Olympus, Tokyo, Japan) and Z-stacking was performed using Imaris software (Bitplane, Belfast, Ireland).

\subsection{Drug Permeability Study}

Sunitinib (LC Laboratories, Woburn, MA, USA) was used as the drug of study due to its intrinsic ability to fluoresce at $540 \mathrm{~nm}$, thus providing an excellent indicator to assess endothelial leakiness [49]. Endothelial cells were first seeded at a density of thirty thousand cells $/ \mathrm{cm}^{2}$ onto 24 -well $6.5 \mathrm{~mm}$ transwell insert, polyester filter with $0.4 \mu \mathrm{m}$ pore (Corning, Corning, NY, USA) for 3 days to form a confluent layer. After 30 min treatment with $\mathrm{TiO}_{2}$ NPs, $100 \mu \mathrm{M}$ of Sunitinib was added into the transwell insert and incubated for another $30 \mathrm{~min}$. Subsequently, $100 \mu \mathrm{L}$ of media was collected from the lower compartment of the transwell and placed into a 96-well black plate. The fluorescence signal was then quantified using Hidex Sense microplate reader (Hidex, Turku, Finland) at Ex405/Em544 nm. To determine the concentration of transported Sunitinib, a standard curve was plotted with concentrations ranging from 0.625 to $40 \mu \mathrm{M}$ and compared against the test samples.

\subsection{Statistical Analysis}

Statistical significance was calculated using a 2-tail equal variance Student's $t$-test comparison, unless otherwise stated. All $p$-values less than 0.05 were considered statistically significant.

\section{Conclusions}

In this study, we showed that $\mathrm{TiO}_{2} \mathrm{NPs}$ could induce transient endothelial leakiness in liver

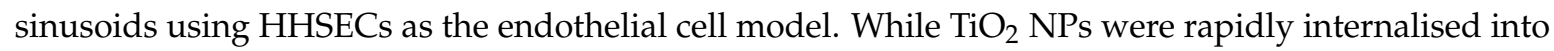
the cells, there were no significant induction of oxidative stress. Instead, we observed a reduction in phosphorylated Akt, which could lead to the detachment of HHSECs. This observation was further supported in our co-culture system, whereby the presence of $\mathrm{TiO}_{2} \mathrm{NPs}$ resulted in the dispersion of endothelial cells from the hepatocytes. Lastly, we showed that NP-induced leakiness could potentially aid in anti-fibrotic therapy through the enhancement of drug transport across a diseased endothelium. Future studies could be aimed at exploring NP-induced leakiness in other liver diseases and designing novel inorganic NPs to specifically target the endothelial cells lining the liver sinusoids while promoting drug uptake.

Supplementary Materials: Supplementary materials can be found at http:/ / www.mdpi.com/1422-0067/20/1/ 35/s1. 
Author Contributions: Conceptualization, J.K.T., D.T.L. and H.K.H.; Data curation, J.K.T., L.Y.N. and H.Y.K.; Formal analysis, J.K.T., L.Y.N. and H.Y.K.; Funding acquisition, H.K.H.; Methodology, J.K.T. and H.K.H.; Resources, D.T.L. and H.K.H.; Supervision, H.K.H.; Writing—original draft, J.K.T., D.T.L. and H.K.H.; Writing一review \& editing, J.K.T., L.Y.N., H.Y.K., D.T.L. and H.K.H.

Funding: This research was funded by Ministry of Education Academic Research Grants (R-148-000-217-112 and R148-000-272-114 to H.K.H.).

Acknowledgments: This study was supported by NUS Department of Pharmacy and NUS Graduate School for Integrative Sciences and Engineering (NGS). We would like to extend our gratitude to Prof. Scott Friedman for the LX2 cells and A/Prof. Victor Yu for the LO2 cells.

Conflicts of Interest: The authors declare no conflict of interest.

\section{References}

1. Heymann, F.; Tacke, F. Immunology in the liver-from homeostasis to disease. Nat. Rev. Gastroenterol. Hepatol. 2016, 13, 88-110. [CrossRef] [PubMed]

2. Griffin, C.T.; Gao, S. Building discontinuous liver sinusoidal vessels. J. Clin. Investig. 2017, 127, 790-792. [CrossRef] [PubMed]

3. Poisson, J.; Lemoinne, S.; Boulanger, C.; Durand, F.; Moreau, R.; Valla, D.; Rautou, P.E. Liver sinusoidal endothelial cells: Physiology and role in liver diseases. J. Hepatol. 2017, 66, 212-227. [CrossRef] [PubMed]

4. Higashi, T.; Friedman, S.L.; Hoshida, Y. Hepatic stellate cells as key target in liver fibrosis. Adv. Drug Deliv. Rev. 2017, 121, 27-42. [CrossRef] [PubMed]

5. Pellicoro, A.; Ramachandran, P.; Iredale, J.P.; Fallowfield, J.A. Liver fibrosis and repair: Immune regulation of wound healing in a solid organ. Nat. Rev. Immunol. 2014, 14, 181-194. [CrossRef] [PubMed]

6. Xu, M.; Wang, X.; Zou, Y.; Zhong, Y. Key role of liver sinusoidal endothelial cells in liver fibrosis. Biosci. Trends 2017, 11, 163-168. [CrossRef] [PubMed]

7. DeLeve, L.D. Liver sinusoidal endothelial cells in hepatic fibrosis. Hepatology 2015, 61, 1740-1746. [CrossRef] [PubMed]

8. Iwakiri, Y. Endothelial dysfunction in the regulation of cirrhosis and portal hypertension. Liver Int. 2012, 32, 199-213. [CrossRef] [PubMed]

9. Zoubek, M.E.; Trautwein, C.; Strnad, P. Reversal of liver fibrosis: From fiction to reality. Best Pract. Res. Clin. Gastroenterol. 2017, 31, 129-141. [CrossRef] [PubMed]

10. Friedman, S.L. Fibrogenic cell reversion underlies fibrosis regression in liver. Proc. Natl. Acad. Sci. USA 2012, 109, 9230-9231. [CrossRef]

11. Fernandez-Iglesias, A.; Gracia-Sancho, J. How to Face Chronic Liver Disease: The Sinusoidal Perspective. Front. Med. 2017, 4, 7. [CrossRef] [PubMed]

12. Nakamura, T.; Sakai, K.; Nakamura, T.; Matsumoto, K. Hepatocyte growth factor twenty years on: Much more than a growth factor. J. Gastroenterol. Hepatol. 2011, 26 (Suppl. 1), 188-202. [CrossRef] [PubMed]

13. Wu, K.; Huang, R.; Wu, H.; Liu, Y.; Yang, C.; Cao, S.; Hou, X.; Chen, B.; Da, I.J.; Wu, C. Collagen-binding vascular endothelial growth factor attenuates CCl4-induced liver fibrosis in mice. Mol. Med. Rep. 2016, 14, 4680-4686. [CrossRef] [PubMed]

14. Nair, H.; Berzigotti, A.; Bosch, J. Emerging therapies for portal hypertension in cirrhosis. Expert Opin. Emerg. Drugs 2016, 21, 167-181. [CrossRef] [PubMed]

15. Ding, X.; Peng, F.; Jun, Z.; Gong, W.; Slaven, G.; Loh, K.P.; Lim, C.T.; Leong, D.T. Defect Engineered Bioactive Transition Metals Dichalcogenides Quantum Dots. Nat. Commun. 2018. [CrossRef]

16. Setyawati, M.; Tay, C.Y.; Chia, S.; Goh, S.; Fang, W.; Neo, M.; Chong, H.C.; Tan, S.; Loo, S.C.J.; Ng, K. Titanium dioxide nanomaterials cause endothelial cell leakiness by disrupting the homophilic interaction of VE-cadherin. Nat. Commun. 2013, 4, 1673. [CrossRef] [PubMed]

17. Peng, F.; Setyawati, M.I.; Tee, J.K.; Ding, X.; Wang, J.; Nga, M.E.; Ho, H.K.; Leong, D.T. Nanoparticles promote in vivo breast cancer cells intravasation and extravasation by inducing endothelial leakiness. Nat. Nanotech. 2018, in press.

18. Setyawati, M.I.; Mochalin, V.N.; Leong, D.T. Tuning Endothelial Permeability with Functionalized Nanodiamonds. ACS Nano 2016, 10, 1170-1181. [CrossRef] [PubMed] 
19. Apopa, P.L.; Qian, Y.; Shao, R.; Guo, N.L.; Schwegler-Berry, D.; Pacurari, M.; Porter, D.; Shi, X.; Vallyathan, V.; Castranova, V.; et al. Iron oxide nanoparticles induce human microvascular endothelial cell permeability through reactive oxygen species production and microtubule remodeling. Part. Fibre Toxicol. 2009, 6, 1. [CrossRef]

20. Setyawati, M.I.; Tay, C.Y.; Bay, B.H.; Leong, D.T. Gold Nanoparticles Induced Endothelial Leakiness Depends on Particle Size and Endothelial Cell Origin. ACS Nano 2017, 11, 5020-5030. [CrossRef]

21. Peng, F.; Tee, J.K.; Setyawati, M.I.; Ding, X.; Yeo, H.L.A.; Tan, Y.L.; Leong, D.T.; Ho, H.K. Inorganic Nanomaterials as Highly Efficient Inhibitors of Cellular Hepatic Fibrosis. ACS Appl. Mater. Interfaces 2018, 10, 31938-31946. [CrossRef] [PubMed]

22. Lalor, P.F.; Lai, W.K.; Curbishley, S.M.; Shetty, S.; Adams, D.H. Human hepatic sinusoidal endothelial cells can be distinguished by expression of phenotypic markers related to their specialised functions in vivo. World J. Gastroenterol. 2006, 12, 5429-5439. [CrossRef] [PubMed]

23. Ding, B.S.; Nolan, D.J.; Butler, J.M.; James, D.; Babazadeh, A.O.; Rosenwaks, Z.; Mittal, V.; Kobayashi, H.; Shido, K.; Lyden, D.; et al. Inductive angiocrine signals from sinusoidal endothelium are required for liver regeneration. Nature 2010, 468, 310-315. [CrossRef] [PubMed]

24. Liu, Y.; Rogel, N.; Harada, K.; Jarett, L.; Maiorana, C.H.; German, G.K.; Mahler, G.J.; Doiron, A.L. Nanoparticle size-specific actin rearrangement and barrier dysfunction of endothelial cells. Nanotoxicology 2017, 11, 846-856. [CrossRef] [PubMed]

25. Liu, X.; Sui, B.; Sun, J. Size- and shape-dependent effects of titanium dioxide nanoparticles on the permeabilization of the blood-brain barrier. J. Mater. Chem. B 2017, 5, 9558-9570. [CrossRef]

26. Saharinen, P.; Eklund, L.; Miettinen, J.; Wirkkala, R.; Anisimov, A.; Winderlich, M.; Nottebaum, A.; Vestweber, D.; Deutsch, U.; Koh, G.Y.; et al. Angiopoietins assemble distinct Tie2 signalling complexes in endothelial cell-cell and cell-matrix contacts. Nat. Cell Biol. 2008, 10, 527-537. [CrossRef] [PubMed]

27. Fukuhara, S.; Sako, K.; Minami, T.; Noda, K.; Kim, H.Z.; Kodama, T.; Shibuya, M.; Takakura, N.; Koh, G.Y.; Mochizuki, N. Differential function of Tie2 at cell-cell contacts and cell-substratum contacts regulated by angiopoietin-1. Nat. Cell Biol. 2008, 10, 513-526. [CrossRef] [PubMed]

28. Sukriti, S.; Tauseef, M.; Yazbeck, P.; Mehta, D. Mechanisms regulating endothelial permeability. Pulm. Circ. 2014, 4, 535-551. [CrossRef]

29. Xiao, W.; Perry, G.; Komori, K.; Sakai, Y. New physiologically-relevant liver tissue model based on hierarchically cocultured primary rat hepatocytes with liver endothelial cells. Integr. Biol. 2015, 7, 1412-1422. [CrossRef]

30. Kang, Y.B.; Rawat, S.; Cirillo, J.; Bouchard, M.; Noh, H.M. Layered long-term co-culture of hepatocytes and endothelial cells on a transwell membrane: Toward engineering the liver sinusoid. Biofabrication 2013, 5, 045008. [CrossRef]

31. Chia, S.L.; Tay, C.Y.; Setyawati, M.I.; Leong, D.T. Decoupling the Direct and Indirect Biological Effects of ZnO Nanoparticles Using a Communicative Dual Cell-Type Tissue Construct. Small 2016, 12, 647-657. [CrossRef] [PubMed]

32. Chia, S.L.; Tay, C.Y.; Setyawati, M.I.; Leong, D.T. Biomimicry 3D gastrointestinal spheroid platform for the assessment of toxicity and inflammatory effects of zinc oxide nanoparticles. Small 2015, 11, 702-712. [CrossRef] [PubMed]

33. Qian, H.; Tay, C.Y.; Setyawati, M.I.; Chia, S.L.; Lee, D.S.; Leong, D.T. Protecting microRNAs from RNase degradation with steric DNA nanostructures. Chem. Sci. 2017, 8, 1062-1067. [CrossRef]

34. Tee, J.K.; Ong, C.N.; Bay, B.H.; Ho, H.K.; Leong, D.T. Oxidative stress by inorganic nanoparticles. Wiley Interdiscip. Rev. Nanomed. Nanobiotechnol. 2016, 8, 414-438. [CrossRef] [PubMed]

35. Li, X.; Zhen, M.; Deng, R.; Yu, T.; Li, J.; Zhang, Y.; Zou, T.; Zhou, Y.; Lu, Z.; Guan, M.; et al. RF-assisted gadofullerene nanoparticles induces rapid tumor vascular disruption by down-expression of tumor vascular endothelial cadherin. Biomaterials 2018, 163, 142-153. [CrossRef]

36. Vestweber, D. VE-cadherin: The major endothelial adhesion molecule controlling cellular junctions and blood vessel formation. Arterioscler. Thromb. Vasc. Biol. 2008, 28, 223-232. [CrossRef]

37. Wang, J.; Zhang, L.; Peng, F.; Shi, X.; Leong, D.T. Targeting Endothelial Cell Junctions with Negatively Charged Gold Nanoparticles. Chem. Mater. 2018, 30, 3759-3767. [CrossRef]

38. Voigt, J.; Christensen, J.; Shastri, V.P. Differential uptake of nanoparticles by endothelial cells through polyelectrolytes with affinity for caveolae. Proc. Natl. Acad. Sci. USA 2014, 111, 2942-2947. [CrossRef] 
39. Liu, X.; Sui, B.; Sun, J. Blood-brain barrier dysfunction induced by silica NPs in vitro and in vivo: Involvement of oxidative stress and Rho-kinase/JNK signaling pathways. Biomaterials 2017, 121, 64-82. [CrossRef]

40. Shetty, S.; Lalor, P.F.; Adams, D.H. Liver sinusoidal endothelial cells-Gatekeepers of hepatic immunity. Nat. Rev. Gastroenterol. Hepatol. 2018, 15, 555-567. [CrossRef]

41. Duan, J.; Yu, Y.; Yu, Y.; Li, Y.; Wang, J.; Geng, W.; Jiang, L.; Li, Q.; Zhou, X.; Sun, Z. Silica nanoparticles induce autophagy and endothelial dysfunction via the PI3K/Akt/mTOR signaling pathway. Int. J. Nanomed. 2014, 9, 5131-5141. [CrossRef] [PubMed]

42. Dimmeler, S.; Fleming, I.; Fisslthaler, B.; Hermann, C.; Busse, R.; Zeiher, A.M. Activation of nitric oxide synthase in endothelial cells by Akt-dependent phosphorylation. Nature 1999, 399, 601-605. [CrossRef] [PubMed]

43. Govers, R.; Bevers, L.; de Bree, P.; Rabelink, T.J. Endothelial nitric oxide synthase activity is linked to its presence at cell-cell contacts. Biochem. J. 2002, 361, 193-201. [PubMed]

44. Bischoff, I.; Hornburger, M.C.; Mayer, B.A.; Beyerle, A.; Wegener, J.; Furst, R. Pitfalls in assessing microvascular endothelial barrier function: Impedance-based devices versus the classic macromolecular tracer assay. Sci. Rep. 2016, 6, 23671. [CrossRef] [PubMed]

45. Ware, B.R.; Durham, M.J.; Monckton, C.P.; Khetani, S.R. A Cell Culture Platform to Maintain Long-term Phenotype of Primary Human Hepatocytes and Endothelial Cells. Cell Mol. Gastroenterol. Hepatol. 2018, 5, 187-207. [CrossRef] [PubMed]

46. Marrone, G.; Shah, V.H.; Gracia-Sancho, J. Sinusoidal communication in liver fibrosis and regeneration. J. Hepatol. 2016, 65, 608-617. [CrossRef] [PubMed]

47. Qu, K.; Huang, Z.; Lin, T.; Liu, S.; Chang, H.; Yan, Z.; Zhang, H.; Liu, C. New Insight into the Anti-liver Fibrosis Effect of Multitargeted Tyrosine Kinase Inhibitors: From Molecular Target to Clinical Trials. Front. Pharmacol. 2016, 6. [CrossRef] [PubMed]

48. Giannitrapani, L.; Soresi, M.; Bondi, M.L.; Montalto, G.; Cervello, M. Nanotechnology applications for the therapy of liver fibrosis. World J. Gastroenterol. 2014, 20, 7242-7251. [CrossRef] [PubMed]

49. Nowak-Sliwinska, P.; Weiss, A.; van Beijnum, J.R.; Wong, T.J.; Kilarski, W.W.; Szewczyk, G.; Verheul, H.M.; Sarna, T.; van den Bergh, H.; Griffioen, A.W. Photoactivation of lysosomally sequestered sunitinib after angiostatic treatment causes vascular occlusion and enhances tumor growth inhibition. Cell Death Dis. 2015, 6, e1641. [CrossRef] [PubMed] 